\title{
HUBUNGAN PARITAS DENGAN SIKAP IBU HAMIL TENTANG KUNJUNGAN KEHAMILAN K1 MURNI DI DESA TANAMERAH KECAMATAN SARONGGI KABUPATEN SUMENEP
}

\author{
Dian Permatasari, Program Studi Kebidanan UNIJA Sumenep \\ e-mail: dianashadi118@gmail.com \\ Eva Nurhidayati, Program Studi Kebidanan UNIJA Sumenep \\ e-mail: vhava_06@yahoo.com
}

\begin{abstract}
Pure Kl coverage is an indicator to know the reach of ANC services to achieve the optimum degree of health especially in pregnancy examination in order to recognize early complications. In fact, there are still many pregnant women who do not do Pure K1, such as coverage of K1 Murni in Tanamerah Village Working Area of UPT Puskesmas Saronggi 53\% from target $87 \%$ until November. The purpose of this research is to know the relation of parity with attitude of pregnant mother about visit of Antenatal care K1 Murni.

The research design was correlational analitic with cross sectional study approach. The population is 46 pregnant women in Tanamerah Saronggi Village from April to May 2014.Total population is 46 respondents. Variable independent is parity and variable dependent is the attitude of pregnant mother in doing visit of pregnancy of K1 Murni. Methods of collecting data in the form of questionnaires and cohorts and then analyzed by statistical test Rank Rank Wilcoxone with $\alpha=0.05$.

Most of pregnant women had more than 1 (Multipara), 34 respondents (73,9\%) and most pregnant women were negative about Pure K1 pregnancy, 33 respondents $(71,7 \%)$. With significance test ( $p$ ) 0.002 which means $p<\alpha$.

Based on the research results can be concluded there is a parity relationship with the attitude of pregnant women to visit pregnancy K1 Murni in Tanamerah Village Work Area UPT Puskesmas Saronggi District Saronggi Sumenep Regency.

Pregnant women and families should increase their willingness and awareness to check their pregnancy according to ANC standard.
\end{abstract}

Keywords: Parity, Attitude, Pure K1

\section{PENDAHULUAN}

Pembangunan Nasional dilaksanakan pada segala bidang, yang tidak kalah pentingnya adalah pada bidang kesehatan. (Undang-undang kesehatan No.25 tahun 1992) (www.depkes.go.id). Di Indonesia, pada tahun 2006 Angka Kematian Ibu cukup tinggi yaitu 307 per 100.000 kelahiran hidup.Jauh melebihi target Nasional yaitu 102 per 100.000 kelahiran hidup. Pada tahun 2007, angkanya menurun menjadi 228 per 100.000 kelahiran hidup,angka ini masih kurang 2 kali lipat dari yang di targetkan.Pada target MDG's lainnya,pencapaian pemerintah sudah cukup terpenuhi. Peraturan Menteri Kesehatan RI Nomor 1457/Menkes/SK/X/2003 tentang Standar Pelayanan Kesehatan Minimal di bidang pelayanan Kesehatan Ibu dan Anak
(KIA) di kota atau kabupaten dengan target 2015, yaitu berupa cakupan kunjungan ibu hamil K1 95\% dan K4 95\%. Berdasarkan Laporan KematianIbu (LKI) Kabupaten atauKota se Jawa Timur tahun 2012, Angka Kematian Ibu di Jawa Timur pada tahun 2012 sebesar 101,4 per 100.000 kelahiran hidup. Tahun 2013 sebesar 104,4 per 100.000 kelahiran hidup sedangkan tahun 2014 turun menjadi 97,4 per 100.000 kelahiran hidup.

Adapun K1 Murni di Indonesia tahun 2014 sebesar $87,37 \%$ belum mencapai target 2015 yang sebesar 95\%.. Provinsi Jawa Timur termasuk provinsi yang belum mencapai target dengan cakupan K1 Murni sebesar 88,82\% (Riskesdes,2015).Untuk program kesehatan ibu dan anak, target pencapaian indikator kinerja tahunan untuk kesehatan ibu, standart 
pelayanan minimal (SPM) adalah 95\%.Kabupaten Sumenep mencapai 84\% (Ditjen Bina Gizi dan KIA KepMenKes RI, 2015). Data yang diperoleh di lapangan Tahun 2015 di UPT Puskesmas Saronggi,cakupan K1

Laporan PWS KIA di Wilayah Kerja Puskesmas Saronggi Kabupaten Sumenep Tahun 2015:

Tabel: 1.1 Data K1 Murni Di Puskesmas Saronggi KabupatenSumenep Tahun 2015

\begin{tabular}{llccc}
\hline NO & \multicolumn{1}{c}{ DESA } & SASARAN & CAKUPAN & Prosentase \\
\hline 1. & SARONGGI & 33 & 21 & $63,64 \%$ \\
2. & TANJUNG & 49 & 41 & $83,67 \%$ \\
3. & TALANG & 94 & 91 & $96,81 \%$ \\
4. & KEBUNDADAP BARAT & 28 & 19 & $67,86 \%$ \\
5. & KEBUNDADAP TIMUR & 44 & 38 & $86,36 \%$ \\
6. & LANGSAR & 46 & 33 & $71,74 \%$ \\
7. & Tanah Merah & 46 & 27 & $54,35 \%$ \\
8. & PAGARBATU & 73 & 57 & $78,08 \%$ \\
9. & JULUK & 41 & 25 & $60,98 \%$ \\
10 & AENGTONGTONG & 21 & 16 & $76,19 \%$ \\
11 & KAMBINGAN TIMUR & 12 & 11 & $91,67 \%$ \\
12 & SAROKA & 33 & 37 & $112,10 \%$ \\
13 & MUANGAN & 12 & 13 & $108,30 \%$ \\
14 & NAMBAKOR & 22 & 24 & $109,10 \%$ \\
\hline
\end{tabular}

Tabel 1.1 bahwa di Desa Tanamerah pencapaian K1 Murni masih dibawah target dan terendah, seharusnya yang harus dicapai tahun 2015 adalah sebesar 87\%, sedangkan di Desa Tanamerah hanya mencapai $54,35 \%$.Sehingga terdapat kesenjangan 32,65 $\%$ dari target $87 \%$ tahun 2015. Dilihat dari fakta tersebut, maka yang menjadi fokus dari permasalahan penelitian ini ialah rendahnya cakupan K1 Murni di Desa Tanamerah Wilayah Kerja UPT Puskesmas Saronggi Tahun 2015 yang mencapai 54,35\% dari target $87 \%$.

Akibat ibu hamil yang tidak melakukan pemeriksaan kehamilan akan meningkatkan angka mortalitas dan morbiditas ibu. Dan dari masalah rendahnya cakupan K1 Murni, yang merupakan SPM di bidang pelayanan Kesehatan Ibu dan Anak (KIA), bila Ante Natal Care tidak dilakukan berdasarkan standar setidaknya sesuai standart akan kurang mendapat informasi seputar kehamilannya. Solusi dari rendahnya cakupan K1 Murni yaitu dengan upaya dari petugas kesehatan untuk mengantisipasi adanya suatu komplikasi pada kehamilan dan persalinan, yaitu meningkatkan pengetahuan dan kesadaran ibu akan pentingnya pemeriksaan kehamilan.
Murni di Desa Tanamerah yang harus dicapai sampai bulan November yaitu $87 \%$, sedangkan di Desa Tanamerah hanya mencapai $54,35 \%$ dan merupakan target terendah.
Berdasarkan data yang didapat di Desa Tanamerah Wilayah Kerja UPT Puskesmas Saronggi Kecamatan Saronggi Kabupaten Sumenep, cakupan K1 Murni pada tahun 2013 sebesar $85 \%$ dan terjadi penurunan pada tahun 2014 sebesar 81\% sedangkan pada tahun 2015 terjadi sebesar 73\% dari target $95 \%$.

Dari hasil survey awal yang telah di lakukan di Desa Tanahmerah Kecamatan Saronggi Kabupaten Sumenep yang di lakukan pada 10 responden yang mengacu pada teori Notoatmodjo (2003), yang mengutip pada pendapat Green ada beberapa faktor yang mempengaruhi rendahnya kunjungan kehamilan K1 Murni. Faktor internal (umur, paritas, sikap, pengetahuan, pendidikan, pekerjaan, persepsi, ekonomi, perilaku, motivasi). Faktor eksternal (sosial budaya, dukungan keluarga, peran kader, perilaku tenaga kesehatan, penyuluhan, media informasi, ketersediaan fasilitas kesehatan, tokoh masyarakat, KIE, lingkungan). Hasil yang paling dominan pada waktu melakukansurvey awal yaitu paritas dengan 7 responden (35\%) dengan sikap 5 responden $(25 \%)$. Berdasarkan hasil survey di atas, peneliti tertarik untuk mengkaji hubungan antaraparitas dengan sikap ibu hamil tentang kunjungan kehamilan K1 Murni di Desa 
Tanamerah Kecamatan Saronggi Kabupaten Sumenep.

\section{METODE PENELTIAN}

Dalam penelitian menggunakan metode penelitian analitik. Sedangkan rancangan penelitian menggunakan merupakan penelitian observasional analitik. Berdasarkan jenis dari rancangannya adalah studi korelasi. Sedangkan berdasarkan waktunya, desain yang digunakan adalah "cross sectional" Dalam penelitian ini variabel independen paritas. variabel dependen pre ibu hamil tentang K1 Murni. Populasi dalam penelitian adalah semua ibu hamil yang sudah melakukan K1 Murni sebanyak 46 orang di Desa Tanamerah UPT Puskesmas Saronggi Kecamatan Saronggi Kabupaten Sumenep Tahun 2015. Sampel dalam penelitian semua ibu hamil yang melakukan kunjungan ANC K1 Murni di Desa Tanamerah pada tahun 2015 yaitu 46 ibu hamil. Pengambilan sampel menggunakan total sampling dengan teknik non random sampling. Dalam penelitian ini peneliti memilih menggunakan quesioner tertutup (Closed ended). Jenis data yang dikumpulkan adalah data primer.

Analisa data adalah bagian dari suatu penelitian. Analisis data dengan pendekatan analitik kualitatif (Hidayat Aziz A,2007). Setelah data terkumpul melalui kuesioner dan dicocokkan dengan data kohort ibu hamil, kemudian hasil jawaban diuji menggunakan uji statistik median dengan bantuan software. Tingkat kemaknaan 5\% H1 diterima artinya ada hubungan antara paritas dengan sikap ibu hamil tentang kunjungan kehamilan K1 murni. Jika $\operatorname{sig}(p)>a=0,05, \mathrm{H}_{0}$ diterima artinya tidak ada hubungan paritas dengan sikap ibu hamil tentang kunjungan kehamilan K1 Murni.

\section{HASIL PENELITIAN}

a. Data Umum

1) Umur

Tabel Distribusi Frekuensi Berdasarkan Umur Ibu Hamil di Desa Tanamerah Wilayah Kerja UPT Puskesmas Saronggi Kecamatan Saronggi.

\begin{tabular}{cccc}
\hline No & Umur & $\sum$ & $\%$ \\
\hline 1 & $<20$ tahun & 2 & $4,30 \%$ \\
2 & $20-35$ tahun & 38 & $82,60 \%$ \\
3 & 35 tahun & 6 & $13,00 \%$ \\
& Jumlah & 46 & $100 \%$ \\
\hline
\end{tabular}

Berdasarkan tabel di atas diketahui bahwa dari 46 ibu hamil di Desa Tanamerah Wilayah Kerja UPT Puskesmas Saronggi Kecamatan Saronggi Kabupaten Sumenep, hampir seluruhnya ibu hamil berumur 20-35 tahun, yaitu sebanyak 38 responden $(82,6 \%)$.

2) Pendidikan

Tabel Distribusi Frekuensi Berdasarkan Pendidikan Ibu Hamil di Desa Tanamerah Wilayah Kerja UPT Puskesmas Saronggi Kecamatan Saronggi Kabupaten Sumenep tahun 2016

\begin{tabular}{cccc}
\hline \multirow{2}{*}{ No } & \multirow{2}{*}{ Pendidikan } & \multicolumn{2}{c}{ Responden } \\
\cline { 3 - 4 } & & $\sum$ & $\%$ \\
\hline 1 & SD & 16 & $34,80 \%$ \\
2 & SMP & 14 & 30.4 \\
3 & SMA & 13 & 28.3 \\
4 & PT & 3 & 6.5 \\
& Jumlah & 46 & $100 \%$ \\
\hline
\end{tabular}

Sumber data primer penelitian tahun 2016

Berdasarkan tabel 4.2 dari 46 responden ibu hamil Desa Tanamerah Wilayah Kerja UPT Puskesmas Saronggi Kecamatan Saronggi Kabupaten Sumenep, hampir setengah ibu hamil pendidikan terakhir adalah $\mathrm{SD}$, yaitu sebanyak 16 responden $(34,8 \%)$.

3) Pekerjaan

Tabel Distribusi Frekuensi Berdasarkan Pekerjaan ibu Hamil Desa Tanamerah Wilayah Kerja UPT Puskesmas Saronggi Kecamatan Saronggi Kabupaten Sumenep

\begin{tabular}{cccc}
\hline \multirow{2}{*}{ No } & \multirow{2}{*}{ Pekerjaan Ibu } & \multicolumn{2}{c}{ Responden } \\
\cline { 3 - 4 } & & $\sum$ & $(\%)$ \\
\hline 1. & Tidak bekerja & 19 & 41.3 \\
2. & Wiraswasta & 24 & 52.2 \\
3. & pegawai & 3 & 6.5 \\
& Jumlah & 46 & $100 \%$ \\
\hline
\end{tabular}

Sumber data primer penelitian tahun 2016

Berdasarkan tabel 4.3 dari 46 responden ibu hamil Hamil Desa Tanamerah UPT Puskesmas Saronggi Kecamatan Saronggi Kabupaten Sumenep, sebagian besar ibu hamil kerja sebagai wiraswasta (petani) sebanyak 24 responden $(52,2 \%)$.

\section{b.) Data Khusus}

1) Paritas

Tabel Frekuensi Berdasarkan Paritas atau jumlah anak ibu di Desa Tanamerah Wilayah 
Kerja UPT Puskesmas Saronggi Kecamatan Saronggi Kabupaten Sumenep

\begin{tabular}{llcr}
\hline \multicolumn{1}{c}{ No } & \multicolumn{1}{c}{ Paritas } & $\sum$ & $\%(\%)$ \\
\hline 1. & Primipara & 6 & $13,00 \%$ \\
2. & Multipara & 34 & $73,90 \%$ \\
3 & Grandemultipara & 6 & $13,00 \%$ \\
Jumlah & & 46 & $100 \%$ \\
\hline
\end{tabular}

Sumber data primer penelitian tahun 2016

Berdasarkan tabel 46 responden ibu Desa Tanamerah Wilayah Kerja UPT Puskesmas Saronggi Kecamatan Saronggi Kabupaten Sumenep, sebagian besar ibu hamil mempunyai anak lebih dari 1 (multipara), yaitu sebanyak 34 responden $(73,9 \%)$.

\section{PEMBAHASAN}

\section{Paritas atau Jumlah Anak Ibu Hamil}

Berdasarkan tabel 5.5 diketahui bahwa dari 46 responden ibu didesa Tanamerah UPT Puskesmas Saronggi Kecamatan Saronggi Kabupaten Sumenep, sebagian besar ibu hamil mempunyai anak lebih dari 1 (multipara), yaitu sebanyak 34 responden (73,9\%). Paritas adalah banyaknya kelahiran hidup yang dipunyai oleh seorang wanita (BKKBN,2006), senada dengan pendapat diatas, Prawirohardjo (2009), mengklasifikasikan paritas menjadi tiga bagian, diantaranya yaitu: primipara, mutipara dan grandemultipara. Berbeda dengan definisi yang dicatat oleh JHPIGO (2008), paritas adalah jumlah kehamilan yang menghasilkan janin yang mampu hidup diluar rahim selama 28 minggu.Sedangkan menurut Manuaba (2008).

Menurut teori Wiknojosastro (2005) bahwa, ibu yang pertama kali hamil merupakan hal yang sangat baru, sehingga termotivasi untuk memeriksakan kehamilannya kepada tenaga kesehatan. Sebaliknya, ibu yang sudah melahirkan lebih dari satu orang anak mempunyai anggapan bahwa ia sudah berpengalaman. Adapun faktor-faktor yang mempengaruhi paritas diantaranya adalah sebagai berikut :

\section{1) Pendidikan}

Pendidikan berarti bimbingan yang diberikan oleh seseorang terhadap perkembangan orang lain menuju ke arah suatu cita-cita tertentu. Makin tinggi tingkat pendidikan seseorang, maka makin mudah dalam memperoleh dan menerima informasi, sehingga kemampuan ibu dalam berpikir lebih rasional. Hampir setengah ibu hamil di desa
Tanamerah berpendidikan terakhir adalah Sekolah Dasar (SD) sehingga informasi yang di dapatkan ibu seputar kehamilan masih sangat kurang dan ibu hamil tidak bisa berpikir rasional tentang kehamilan sedangkan ibu yang mempunyai pendidikan tinggi akan lebih berpikir rasional bahwa jumlah anak yang ideal adalah dua orang.

2) Pekerjaan

Pekerjaan adalah simbol status seseorang dimasyarakat. Pekerjaan jembatan untuk memperoleh uang dalam rangka memenuhi kebutuhan hidup dan untuk mendapatkan tempat pelayanan kesehatan yang diinginkan. Sebagian besar ibu dan suami responden bekerja sebagai wiraswasta atau swasta sehingga mereka mempunyai anggapan bahwa mereka boleh mempunyai banyak anak karena merasa mampu dalam memenuhi kebutuhan sehari-hari.

Dari wawancara atau kuisioner untuk mengetahui paritas dan sikap ibu hamil disini yaitu dengan menanyakan tentang isi materi untuk mengukur sikap dari subjek penelitian atau responden tentang paritas dan bagaimana sikap ibu hamil dalam melakukan kunjungan kehamilan K1 Murni.Ibu yang sudah pernah melahirkan mempunyai anggapan bahwa ia sudah berpengalaman sehingga tidak termotivasi untuk memeriksakan kehamilannya dan akan mempengaruhi pada sikap ibu dalam kunjungan kehamilan K1 murni.Sikap ibu tentang pemeriksaan kehamilan yang masih kurang dapat dilihat dari frekuensi kunjungan pemeriksaan selama kehamilan.

Dan dari hasil survey di lapangan banyak ibu hamil yang tingkat paritasnya adalah multipara, dimana pada hasil kuesioner banyak ibu yang bersikap negatif dalam melakukan kunjungan kehamilan K1 Murni. Dalam hal ini terdapat kesenjangan antara teori dan keadaan di lapangan, yang menunjukkan bahwa tingkat paritas sangat berpengaruh bagi seseorang dalam bersikap, membuat suatu keputusan, memahami, serta mengambil tindakan terhadap suatu hal. Hal tersebut menandakan semakin tinggi tingkat paritas,maka ibu akan semakin bersikap negatif dalam melakukankunjungan kehamilan dan merupakan salah satu faktor yang menjadi 
penyebab ibu hamil tidak melakukan pemeriksaan kehamilan K1 Murni.

Upaya yang perlu dilakukan untuk tingkat paritas ibu yang tinggi dan yang bersikap negatif yaitu dapat dilakukan oleh pemerintah bersama Dinas Kesehatan dan para tenaga kesehatan, terutama bidan dengan cara memberikan motivasi, informasi, dan penyuluhan secara teratur dan kontinyu seputar tentang kunjungan kehamilan agar ibu lebih mengerti atau memahami manfaat ANC dan dampak jika tidak memeriksakan kehamilannya sesuai standart ANC yang telah ditetapkan.

\section{Sikap ibu Hamil tentang Kunjungan Kehamilan K1 Murni}

Berdasarkan tabel 5.7 diketahui bahwa sebagian besar ibu hamil bersikap negatif dalam melakukan kunjungan kehamilan K1 Murni, yaitu sebanyak 33 responden $(71,7 \%)$. Sikap menurut Notoatmodjo (2003) adalah merupakan reaksi atau respon seseorang yang masih tertutup terhadap suatu stimulus atau objek. Sikap dapat dipahami sebagai kecenderungan bertindak dari individu, berupa respon tertutup terhadap stimulus ataupun objek tertentu atau sikap merupakan reaksi atau respon yang masih tertutup dari seseorang terhadap suatu stimulus atau objek. Sikap menurut ahli psikologi thurstone dan Osgood adalah suatu bentuk evaluasi atau reaksi perasaan, sikap seorang terhadap objek adalah adalah prasaan mendukung atau memihak (favorable) ataupun perasaan tidak mendukung (unfavorable) objek tersebut.

Penghitungan tingkatansikap dapat sebagai kontrol bahwa pelaksana program telah melaksanakan program sesuai standart. Dalam hal dapat diartikan tindakan yang berkaitan dengan tindakan seseorang dalam berkunjung ke tempat pelayanan kesehatan oleh ibu hamil sesuai dengan saran petugas kesehatan dan dengan standart Antenatal Care (ANC) yang ditetapkan (Notoatmodjo, 2003). Dengan standart kunjungan kehamilan minimal 4 kali, yaitu 1 kali pada trimester pertama, 1 kali pada trimester kedua, dan 2 kali pada trimester ketiga sesuai yang ditetapkan. Bila ibu tidak melakukan kunjungan sesuai dengan standart tersebut dapat dikatakan bahwa ibu tersebut bersikap unfavorabledalam melakukan kunjungan kehamilan (Depkes RI, 2004). Sedangkan ibu yang melakukan kunjungan kehamilan K1 Murni dapat di katakana ibu tersebut favorable dalam melakukan kunjungan kehamilan K1 Murni. Dan disini yang mempengaruhi sikap seseorang meliputi faktor ekstern yaitu: dorongan, lingkungan, kebudayaan, lembaga pendidikan, teman sebaya, media massa, dan faktor ekstern yaitu: kebiasaan, ketertarikan, pengalaman dan sosial ekonomi. Menurut Smet (1994) dalam Notoatmodjo (2003) adapun berbagai strategi telah dicoba untuk mengubah sikap ibuyaitu dukungan profesional kesehatan sangat diperlukan untuk mengubah sikap, contoh yang paling sederhana dalam hal dukungan tersebut adalah dengan adanya teknik komunikasi. Komunikasi memegang peranan penting karena komunikasi yang baik diberikan oleh profesional kesehatan baik dokter/ perawat dapat menanamkan sikap yang positif bagi pasien, dukungan sosial dari keluarga untuk menunjang peningkatan kesehatan pasien agar ibu hamil yang tidak mau memeriksakan kehamilannya pada trimester pertama dapat dikurangi, dan pemberian informasi yang jelas seputar kehamilan.

Dan pada kenyataan disini yaitu setelah melihat pada register kohort untuk sikap ibu, banyak ibu hamil yang tidak mau memeriksakan kehamilannya terutama pada kunjungan kehamilan K1 Murni. Hal tersebut spesifik antara teori dan kenyataan pada lapangan yang menandakan bahwa sikap negatifibu hamil dalam melakukan kunjungan kehamilan K1 Murni yaitu tidak sesuai dengan standart ANC yaitu minimal 1 kali pada trimester pertama, 1 kali pada trimester kedua, dan 2 kali pada trimester ketiga.

Upaya yang perlu dilakukan, kita sebagai tenaga kesehatan masih mempunyai kesempatan untuk meningkatkan keberhasilan program dengan cara memberikan penyuluhan secara teratur dan kontinyu tentang pentingnya kunjungan kehamilan K1 Murni yang mana pemeriksaan kehamilan pada TM I untuk mendeteksi adanya komplikasi kehamilan, sehingga jika ada kelainan bisa terdeteksi agar dapat menyelesaikan kehamilannya dengan baik dan 
melahirkan bayi yang sehat, dan dari pelaksanaan kesehatan ini agar kunjungan ibu hamil meningkat dan status K1 Murni ibu hamil tercapai, persalinan ditolong oleh tenaga kesehatan.

\subsubsection{Hubungan Paritas dengan sikap Ibu Hamil Tentang Kunjungan Kehamilan K1 Murni}

Dari hasil uji statistik korelasi Sign Rank Wilcoxonw dengan tingkat signifikas $<\alpha=0,05$. Didapatkan signifikasi uji (p) 0,002 yang berarti $\mathrm{p}<\alpha(\alpha=0,05)$ sehingga $\mathrm{H} 1$ diterima yang artinya ada hubungan antara paritas dengan sikap ibu hamil tentang kunjungan kehamilan K1 Murni tahun 2016.

Dari hasil tabulasi silang 5.7 dapat diketahui bahwa ibu hamil yang memiliki paritas primipara hampir seluruhnya bersikap positif dalam melakukan kunjungan kehamilan K1 Murni yaitu sebanyak 5 responden (83\%), untuk ibu hamil yang memiliki paritas lebih dari satu (multipara) hampir seluruhnya bersikap negatif dalam melakukan kunjungan kehamilan K1 Murni yaitu sebanyak 27 responden $(79,5 \%)$, dan ibu hamil yang memiliki paritas lebih dari 5 anak (grandemultipara) hampir seluruhnya bersikap negatif dalam melakukan kunjungan kehamilan K1 Murni yaitu sebanyak 5 responden (83\%).

Ibu yang memiliki lebih dari satu orang anak yaitu multipara / grandemultipara mempunyai kecenderungan untuk tidak melakukan tindakan yang diharapkan dan bersikap negatif dalam melakukan kunjungan kehamilan K1 Murni. Menurut teori Wiknojosastro (2005) bahwa, ibu yang pertama kali hamil merupakan hal yang sangat baru, sehingga termotivasi untuk memeriksakan kehamilannya kepada tenaga kesehatan. Sebaliknya, ibu yang sudah melahirkan lebih dari satu orang anak mempunyai anggapan bahwa ia sudah berpengalaman.

Menurut hasil penelitian dari dr. Siti Candra, SpOG (2005), mengatakan bahwa ada hubungan antara paritas dengan keteraturan kunjungan kehamilan. Dimana semakin rendah tingkat paritasnya, maka akan semakin baik pula sikap ibu dalam melakukan kunjungan kehamilan. Ibu yang sudah melahirkan lebih dari satu orang anak mempunyai anggapan bahwa ia sudah berpengalaman sehingga ibu akan enggan untuk mengetahui informasi seputar kehamilannya dan akan melakukan tindakan dengan bersikap negatif dalam memeriksakan kehamilannya, dan hal ini dapat dipengaruhi oleh beberapa faktor yaitu umur, pendidikan, pekerjaan.

Pada faktor umur, Menurut

(Notoatmoedjo, 2010) bahwa, semakin bertambahnya umur seseorang maka kematangan dalam berfikir semakin baik sehingga akan termotivasi dalam memeriksakan kehamilan. Pada penelitian ini menunjukkan bahwa sebagian besar ibu hamil berumur 20-35 tahun, yaitu sebanyak 38 responden $(82,6 \%)$ dengan tingkat paritas multipara.

Kenyataan ini tidak sesuai dengan teori yang ada, yang mana kenyataan di lapangan menunjukkan responden yang yang cukup umur sebagian besar bersikap negatif dalam melakukan kunjungan kehamilan K1 Murni, hal ini di sebabkan karena tingkat paritas responden yaitu multipara, dimana responden berfikir bahwa ia telah memiliki pengalaman hamil sebelumnya sehingga responden enggan untuk melakukan kunjungan kehamilan K1 Murni.

Pada faktor pendidikan, pendidikan berarti bimbingan yang diberikan oleh seseorang terhadap perkembangan orang lain menuju ke arah suatu cita-cita tertentu. Makin tinggi tingkat pendidikan seseorang, maka makin mudah dalam memperoleh dan menerima informasi, sehingga kemampuan ibu dalam berpikir lebih rasional. Ibu yang mempunyai pendidikan tinggi akan lebih berpikir rasional bahwa jumlah anak yang ideal adalah dua orang.Pada penelitian ini menunjukkan bahwa hampir setengahnya yaitu $(34,8 \%)$ responden berstatus sebagai lulusan Sekolah Dasar (SD) yang tingkat paritasnya multipara. Dalam hal ini spesifik antara teori dan kenyataan yang ada di lapangan, di mana kenyataan yang ada di lapangan untuk responden yang berpendidikan rendah sangat sulit untuk melakukan kunjungan kehamilan K1 Murni karena informasi yang ia dapatkan seputar kehamilan masih sangat kurang di tambah dengan pengalaman hamil yang sudah di alami sebelumnya. 
Pada faktor pekerjaan, menurut (Notoatmoedjo, 2005) bahwa, dengan adanya pekerjaan seseorang akan memerlukan waktu dan tenaga untuk menyelesaikan pekerjaanya. Masyarakat yang sibuk dalam dunia kerja, bisa di pastikan hanya memiliki waktu yang sedikit untuk memeriksakan kehamilannya. Pada penelitian ini menunjukkan bahwa hampir setengah ibu hamil bekerja sebaga petani (wiraswasta), yaitu sebanyak 24 responden $(52,3 \%)$. Yang mana bila seseorang ibu ikut membantu penghasilan dalam rumah tangga maka pada saat hamil mereka lebih banyak mengeluarkan tenaga dan pikiran maka efeknya dapat berpengaruh pada pemeriksaan kehamilan. Pekerjaan sangat menentukan terhadap seseorang untuk berbuat sesuatu kegiatan. Pekerjaan yang dimaksud adalah pekerjaan ibu, dengan banyak kesibukan maka ibu kadang-kadang lupa untuk melakukan pemeriksaan kehamilan tepat waktu sehingga mempengaruhi sikap ibu dalam melakukan kunjungan kehamilan K1 Murni.

Dari hal-hal di atas akan mempengaruhi keberhasilan pemerintah dalam menurunkan AKI dan AKB, maka dari itu kita sebagai tenaga kesehatan masih mempunyai kesempatan untuk meningkatkan keberhasilan program dengan cara memberikan penyuluhan secara teratur dan kontinyu tentang pentingnya kunjungan kehamilan K1 Murni. Oleh karena itu, jika ibu hamil mengerti dan memahami tentang pentingnya kunjungan kehamilan K1 Murni, maka ibu tersebut akan lebih termotivasi dan akan bersikap positif dalam memeriksakan kehamilannya.

Dan dalam peningkatan sikap ibu hamil untuk melakukan ANC, promosi kesehatan, penyuluhan kesehatan dan konseling dijadikan suatu solusi utama dalam upaya meningkatkan kunjungan kehamilan K1 Murni terutama untuk melakukan pemeriksaan kehamilan secara teratur.

\section{PENUTUP}

\section{Kesimpulan}

1) Paritas atau jumlah anak yang dilahirkan oleh ibu hamil di desa Tanamerah adalah sebagian besar ibu hamil memiliki paritas multipara.
2) Sikap ibu hamil dalam melakukan kunjungan kehamilan K1 Murni sebagian besar ibu hamil bersikap negatif tentang kunjungan kehamilan K1 Murni di Desa Tanamerah.

3) Ada hubungan antara paritas dengan sikap ibu hamil dalam melakukan kunjungan kehamilan K1 Murni Di Desa Tanamerah.

\section{Saran}

1) Bagi Peneliti

Menambah pemahaman peneliti dalam memahami tingkat pengetahuan dan sikap ibu hamil atau masyarakat tentang pentingnya kesehatan kehamilan

2) Memberikan pengalaman baru sebagai upaya pengembangan diri sendiri dalam mengemban tugas dan beban sebagai tenaga kebidanan yang akan memegang utuh tanggung jawab dalam memberikan pelayanan kesehatan yang baik kepada masyarakat.

3) Bagi Pelayanan Kesehatan

Hendaknya meningkatkan konseling dan penyuluhan tentang pentingnya pemeriksaan kehamilan ke tenaga kesehatan dengan standart minimal; 1 kali pada trimester I yaitu kunjungan kehamilan K1 Murni untuk memberikan informasi seputar makan bergizi bagi ibu hamil, menjaga kebersihan diri dan mengatur pola istirahat, untuk mendeteksi tanda bahaya kehamilan secara dini seperti anemia kehamilan yang dapat menyebabkan perdarahan pada saat persalinan, untuk mendeteksi adanya penyulit saat persalinan seperti kelainan bentuk panggul atau kelainan pada bentuk tulang belakang atau kehamilan ganda. 1 kali pada trimester II, dan 2 kali pada trimester III.

4) Bagi Institusi Pendidikan

Hendaknya penelitian ini dapat dijadikan sebagai salah satu sumber pengetahuan dalam pendidikan tentang masalah hubungan paritas dengan sikap tentang kunjungan kehamilan K1 Murni.

5) Bagi Peneliti Berikutnya

Perlu dilakukan penelitian lebih lanjut tentang hubungan kunjungan kehamilan K1 Murni dengan variabel yang belum diteliti dalam penelitian ini. 
6) Bagi Masyarakat

Agar dapat lebih memahami tentang pentingnya melakukan pemeriksaan kehamilan secara rutin kepada tenaga kesehatan.

\section{DAFTAR PUSTAKA}

Alimul, Aziz. (2007). Riset Keperawatan dan Teknik Penulisan Ilmiah. Jakarta: Salemba Medika.

(2008). Pedoman Diagnosis dan Terapi bag/smf ilmu kebidanan dan penyakit kandungan. Rumah Sakit Umum Dokter Soetomo Surabaya.

Atmadja, Surya dkk. (2004). ACSM: Panduan Uji Latihan Jasmani dan Peresapannya. Jakarta: EGC.

(http://olahraga.kompasiana.com/atletik,di akses 30 Maret 2012).

Cunningham, dkk. (2006). Obstetri Williams. Jakarta:EGC.

Fatimah. (2006). Pelayanan Persalinan yang Aman. Jakarta.

Hartman, Tom (2008). Terapi Jalan Kaki. Jakarta: Salemba Medika

Hovatta dan Lipasti. (2007). www.undip.ac.id diakses tanggal 28 Februari 2012

Mitrariset, (2005). Konsep Dasar Ibu Hamil. Jakarta.

Notoatmodjo, Soekidjo. (2005). Metodologi Penelitian Kesehatan. Jakarta: Rineka Cipta.

Nursalam. (2003). Konsep dan Penerapan Metodologi Penelitian Ilmu Keperawatan: Pedoman Skripsi, Tesis dan Instrumen Penelitian Keperawatan Edisi 1. Jakarta: Salemba Medika.

Nursalam. (2008). Konsep dan Penerapan Metodologi Penelitian Ilmu Keperawatan: Pedoman Skripsi, Tesis dan Instrumen Penelitian Keperawatan Edisi 2. Jakarta: Salemba Medika.

Pramono, Djoko. (2009). Olahraga Pada Kehamilan. Jakarta: CV Sportisi Indonesia.http://www.dianweb.org/Sehat/ ADI3.HTM, diakses 12 April 2012

Prasetyo, yudik (2011) Olahraga dan Kehamilan Jakarta: CV Sportisi Indonesia.http://www.dianweb.org/Sehat/ ADI3.HTM, diakses 12 April 2012
Rushal, Pyke. (2003). Latihan kondisi fisik. Jakarta: CV Andi

http://tubuhsehat.blogdetik.com/, diakses 12 April 2012

Saifuddin, dkk. (2006). Buku Panduan Praktis Pelayanan Kesehatan dan Maternal. Jakarta: Yayasan Bina Pustaka Sarwono Prawirohardjo.

Saifuddin, dkk. (2006). Buku Panduan Praktis Pelayanan Kesehatan dan Maternal. Jakarta: Yayasan Bina Pustaka Sarwono Prawirohardjo.

Saifuddin, dkk. (2008). Ilmu Kebidanan. Jakarta: Yayasan Bina Pustaka Sarwono Prawirohardjo.

Santoso, Singgih. (2003). Statistik Non Parametik Cet. 3. Jakarta: Elex Media Computindo.

Supari. (2008). www.undip.ac.id diakses tanggal 28 Februari 2012

Susilo, Yekti. (2011). Cara Jitu Mengatasi Hipertensi. Yogyakarta: CV Andi Offset.

Varney, dkk. (2006). Buku Ajar Asuhan Kebidanan Vol 2. Jakarta: EGC

Widyastuti, Lestari. (2007). Tetap Bugar Ketika Hamil. Jakarta: CV Sportisi Indonesia. (http://olahraga.kompasiana.com/atletik,di akses 30 Maret 2012).

Winkjosastro, dkk. (2006). Ilmu Kebidanan. Jakarta: Yayasan Bina Pustaka Sarwono Prawirohardjo.

Wiyono,(2012)http:tubuhsehat.blogdetik.com/2 009/03/13/manfaat-jalan-kaki-secara-rutin

Pusdiknakes-WHO-JHPIEGO, (2003) Panduan Pengajaran Asuhan Kebidanan Bagi Dosen Diploma II Kebidanan, Buku 2 Agustus Antenatal Pusdinkes, Jakarta.

Prawirohardjo, Sarwono. (2006). Buku Acuan Nasional Pelayanan Kesehatan. Bina Pustaka, Jakarta.

Prawirohardjo, Sarwono. (2007). Ilmu Kebidanan. Jakarta : Yayasan Bina Pustaka

Prawirohardjo, Sarwono. (2009). Buku Acuan Nasional ilmu kebidanan. Bina Pustaka, Jakarta.

Prawirohardjo, Sarwono. (2010). Buku Acuan Nasional Pelayanan Kesehatan. Bina Pustaka, Jakarta.

Sulistyawati, Ari (2009). Asuhan Kebidanan. Jakarta:SalembaMedika 